\title{
The semantics of English Borrowings in Arabic Media Language: The case of Arab Gulf States Newspapers
}

\author{
Anwar A. H. Al-Athwary \\ Department of English, Faculty of Science and Arts, Najran University, Saudi Arabia \\ E-mail: anwaraha@yahoo.com
}

Received: 17-02-2016

Published: 01-07-2016
Accepted: 26-04-2016

doi:10.7575/aiac.ijalel.v.5n.4p.110
Advance Access Published: May 2016

URL: http://dx.doi.org/10.7575/aiac.ijalel.v.5n.4p.110

\begin{abstract}
The present paper investigates the semantics of English loanwords in Arabic media language (AML). The loanword data are collected from a number of Arab Gulf states newspapers (AGSNs). They are analyzed semantically from the points of view of semantic change, semantic domains, and the phenomenon of synonymy resulting from lexical borrowing. The semantic analysis has revealed that AML borrowings from English occur in fifteen distinctive semantic domains. Domains that are related to terms of technical and scientific nature are found ranking much higher $(9 \%-18 \%)$ than those domains containing nontechnical elements $(1 \%-8 \%)$ with the computer and technology category $(18 \%)$ is the most dominant domain. Almost all common mechanisms of semantic change (extension, restriction, amelioration, pejoration, and metaphorical extension) are found at work in the context of AML borrowings. The tendency of semantic change in the overwhelming majority of AML borrowings is towards restriction. Factors like need, semantic similarity, and factors of social and psychological considerations (e.g. prestige, taboo) seem to be the potent factors at interplay in semantic change. The first two, i.e. need and semantic similarity, are the most common reasons in most types of semantic change. The problem of synonymy lies in those loanwords that have "Arabic equivalents" in the language. The study claims that this phenomenon could be attributed to the two simultaneous processes of lexical borrowing and?ištiqa:q (the modern efforts of deriving equivalent neologisms).
\end{abstract}

Keywords: loanwords, semantic change, semantic domains, synonymy, Arabic media language

\section{Introduction}

In the modern era, the influence of western languages (particularly English), as languages of both the traditional colonizers and the present dominant civilization, on Arabic is the more serious and widespread than that of any other languages of today (Boyle 2012, Mahmoud 2013, Newman 2002, Vasteegh 2010). With the modern technological and cultural developments that have taken place in the world and their recent echoes in the Arab world, an urgent need has arisen for transferring many technical concepts into Arabic in many fields. As a result, Arabic finds itself face to face with an immense number of foreign terminology.

In the last four decades, Arabic media in general and Arabian Gulf media in particular has been invaded by tens of foreign elements borrowed from English language to fill a lexical need in written Arabic due to the strong presence of English in the various spheres of life. In the context of Arab Gulf states, English is employed in education, mass media, translation work, commercial and economic links and the Internet which possibly represent points of contact that certainly facilitate and reinforce the borrowing process from English into Arabic. Furthermore, as Weber reports, "many laborers in the Gulf hail from former English colonies (Pakistan and India) where English still exists as an important language. English, therefore, acts as a key lingua franca among different expatriate nationalities and between Arabs and expatriates ... In some Gulf countries, the expatriate population makes up over 81\%" (Weber 2011: 63). As a result, the presence of this large number of expatriate labor force represents another source of influence of the accommodation of English borrowings into Arabic.

When borrowed, not only the phonological and morphological shapes of loanwords are modified, the meaning of such loans may also undergo significant adaptations. The focus in this study, therefore, will be only the semantic implications of English loanwords as used in Arabic online newspapers of Arab Gulf states.

\section{The purpose of the study}

The semantics of English borrowings found in Arab Gulf States newspapers (AGSNs) will be investigated from three points of view:

1. A general analysis of Arabic loanwords from English will be carried out to know the extent of lexical borrowing in various significant semantic fields and which domains are most likely to borrow from.

2. My principal concern, however, is to examine the semantic changes the borrowed items may undergo in the course of lexical borrowing and discuss the main factors that may lie behind such semantic directions. 
3. The issue of linguistic synonymy in Arabic, as a consequence of lexical borrowing on one hand and as analogical derivation (?ištiqa:q) of native neologisms on the other, will be taken into consideration.

\section{Earlier studies}

The semantic study of English loanwords in Arabic has received scant attention in the literature in comparison to loanword phonology and loanword morphology. In terms of generative phonology, Thornburg (1980) studies 283 English words as used in East District Saudi Arabic. Alterations made in consonantal segments and sequences in such English loans and their effects on Arabic phonology are examined. Thornburg comes out with a set of phonological rules which she calls "borrowing rules". Heath (1989) deals with the issues of borrowing and code-switching but in Moroccan Arabic. Heath's study indeed is a thorough coverage of the post-colonial linguistic contact in Morocco. Borrowings from western languages, mainly French and Spanish, as well as from Classical Arabic are morphophonemically and semantically (just patterning the loans into their lexical domains) analyzed. Code-switching from these languages are dealt with, by the author, as "an avenue to borrowing".

The only semantic study of loanwords that I came across is Bader (1990). The study, however, focuses only on the semantic change of loanwords borrowed by Jordanian Arabic (JA) from English and French. It examines the different semantic forms like widening, narrowing, transfer, and shift that loanwords in JA may undergo. The main difference between Bader's study and the present one is that the former deals with loanwords as used in a dialect or a colloquial variety of Arabic, i.e. JA while the latter deals with loanwords as used in a standard variety of Arabic , i.e. Arabic media language (AML). The difference lies in the fact that loanwords elements used in each variety are, in most cases, not the same. Examples that Bader provides throughout his article like narsah $<$ nurse, tanakah $<$ tin can , sufer $<$ French chauffeur, kawboy < cowboy, etc. have never been incorporated into AML lexicon. No doubt that there are some loans which are common in both varieties. What is crucial here, however, is that in the two varieties such loans behave differently in terms of semantic change; that is elements like ra:dyo $<$ radio, karto:n $<$ carton, blasti:k $<$ plastic, etc. do involve some kind of semantic change in Bader (1990) (see pp. 38- 42), while they don't in AML as we will see below.

Al-Qinai (2000) investigates certain morphophonemic changes that loanwords have undergone to conform to Arabic phonotactics and morphological patterns in the light of traditional insights and implications made forward by Sibawayh, al-Jawhariyy, al-Jawaliqiyy, etc. Regarding, the loanword corpus used, the analysis draws heavily on old borrowings from Persian, Greek, Syriac, etc. which entered Classical Arabic in pre-Islamic and Medieval periods and which were already recognized by the Medieval scholars. From the point of morphology, Al-Saidat (2011) examines the gender and number assignment of English loanwords in Jordanian Arabic. He concludes that English loanwords in Jordanian Arabic follow the Arabic language system rather than the English language system. As a result, they can be considered as borrowed items rather than code switches. Jarrah (2013) focuses on English loanwords phonology in Madina Hijazi Arabic (MHA) from the point of view of Optimality Theory. The article discusses the phonological changes that occur in English loanwords frequently used by MHA speakers, mainly in syllable structure. Mahmoud (2013) investigates the influence of English on MSA in general. The focus is on what the author calls "reverse transfer", i.e. the influence of English on Arabic rather than the effect of mother tongue (Arabic) on English. The study discusses the most common linguistic manifestations of this reverse interlingual transfer. Among these are poor translation, calquing, borrowing, substitution, re-ordering, and code mixing. It also enumerates some of the detrimental effects of reverse cross-linguistic transfer from English to MSA: linguistic invasion, 'foreignness', alienation of the audience and the speaker/writer, incomprehensibility, misunderstanding, and exposing readers to poor and incorrect MSA.

To the best of the author's knowledge, there seems to be no single study that probed for semantic perspectives of English loanwords in Arabic language as shown by Arabic media language.

\section{Data collection and methods}

The present study deals with English borrowings used in AML. Therefore, six online newspapers in the Arab Gulf area were selected to be used as the main source of data; the online newspapers involved in the study are Al-Sharq AlAwasat newspaper (Saudi Arabia), Al-Anba'a newspaper (Kuwait), Al-Raya newspaper (Qatar), Al-Emarat Al-Yawm newspaper (United Arab Emirates), Al-Wasat newspaper (Bahrain), and Al-Watan newspaper (Oman). 291 English loanwords have been collected in the period of June to August 2015. The study focuses on the most recent English elements that have been incorporated into Arabic in the modern age. The collected data are restricted to borrowing proper (e.g. arši $: f<$ archive) and exclude the productive (derivative) forms (e.g. aršafah 'the process of using archives', arši:fiyy 'related to the use of archives', etc.). Further, the brand names (car brands, goods brands, etc.) have been excluded, too. Categories of this kind usually belong to what is sometimes known in the literature as "modern internationalisms" or "globalisms", words or expressions used by the inhabitants of the global village (Witalisz 2011:2) and usually incorporated from different languages, not necessarily from English alone. Each element in the collected data, then, is recoded one time and the frequency of occurrence of the same element is not accounted for (cf. Abdul Razak 2011; Mahmoud 2013). The selection of the online newspapers is based on two things: first, whether the newspaper includes a wide range of language registers (politics, business, sports, technology, etc,), and second whether the newspaper is acquainted with advanced research device. This device helps in making sure whether a potential loanword exists in the news story or not. 
The variety of Arabic used in the current study is modern standard written Arabic, a variety which is the language of newspapers and which is categorized, in a diaglossic situation, as the high variety in comparison with non-standard varieties which are classified as the low variety.

Almost all collected loanwords in this study are nouns. This statement is in line with what agreed upon in the literature that the overwhelming majority of loans is nominal in nature (see Versteegh 2009). Modern standard Arabic rarely borrows verbs directly into its lexicon. Non-standard varieties, however, do incorporate verbs as Versteegh argues throughout his article on loan verbs in some Arabic dialects.

Since the loanword data compiled are of a written nature, the researcher, as a native speaker of Arabic, serves as an informant in establishing the pronunciation and meanings of loanword data.

\section{Results and discussion}

\subsection{Semantic domains of English loanwords used in AGSNs}

In the semantic field theory (Lehrer 1974, 1985), a semantic field is defined as a group of words/ lexemes which cover a certain conceptual domain and which bear certain specifiable relations to one another. Similarly, Finegan and Besnier (1989: 179) refer to the term as "a set of words with identifiable semantic affinities". For instance, in English, the words in the domain of internet fall under the general term 'internet' and include 'e-mail' 'website', 'homepage', 'chat', '(main) server', and tens of others.

Linguistic description at all levels tends to be stated in that they present the linguistic facts in a more idealized way than is found when used dynamically by speakers (Lehrer 1974: 19). There are often areas of overlap among different semantic domains, though, it is more common in one specific domain. The Arabicized word ?istira:ti:jiyyah 'strategy', for example, is always related to the political and military domain but it could be further used in other domains as in ?istira:ti:jiyijatu ta3li:m 'education strategy', ?al-?istira:ti:jiyyatu l-?iqtişa:diyyah 'the economic strategy'. Similarly, the borrowed term ka:btin from 'captain', belongs to both military and sports domains, and so on.

Taking the above implications into consideration, the present data of 291 cases that constitute the AML borrowing proper, can be roughly classified into the following fifteen semantic domains listed in (1) below with their approximate percentage and some selected examples:

(1)

\section{Semantic domain}

Administration and Business

Animals

Arts and education

Building and construction

Clothing and fashion

Computer and technology

Food and drinks

Medicine

Music and entertainment

Politics and military

Religion

Sports and games

Transport and communication

Weight and measurement

Miscellaneous

Total

\section{No. \& \% Examples of loans and their original forms}

14/ 5\% ši:k 'cheque' ?arši:f 'achieves'?ubik 'OPEC'

$4 / 1 \%$

$25 / 9 \%$

$10 / 3 \%$

$8 / 3 \%$

$53 / 18 \%$

$25 / 9 \%$

$25 / 9 \%$

$24 / 8 \%$

šamba:nzi 'chimpanzee' gurilla 'gorilla'

munulu:j 'monologue' ru:mansiyyah 'romancism' dublu:m 'diploma' burufisu:r 'professor'

warni: ̌s 'varnish'?ismant 'cement' jara: ̌s 'garage'

ja:kit 'jacket' mu:di:l model

mu:di:m 'modem' i:mi:l e-mail ?intarnit 'internet'

?iskanar'scanner'

Sandawitš 'sandwich' kayk 'cake' kafiti:riya: 'cafeteria' bibsi 'Pepsi'

?asbiri:n 'aspirin' rumati:zm 'rheumatism'

hurmu:n 'hormone'

ka:sit 'cassette' ji:ta:r 'guitar' ja :z 'jazz'

?isti:riyu: 'stereo

sinatu:r 'senator' takt:k 'tactic' congris 'congress' fitu:

38/13\% 'vito' ma:ri:nz 'marines' lu:bi'lobby' hu:lukubtar helicopter'

3/ 1\% kirismis' Christmas’ ka:Ouli:k Catholic’

tinis 'tennis' maraAu:n 'marathon' bala:nti

'penalty'

28/ 10\% tilifu:n 'telephone' taksi 'taxi'

10/3\% ?inš/ hinš 'inch' fult 'volt' ţann 'ton'

$12 / 4 \%$

?ista:ti:kiyyah 'statics' jiyu:lu:jiya: 'geology'

$291 / 100 \%$

Almost all loanwords in different domains in the list above designate non-indigenous cultural concepts typical of western civilization. The frequency and percentage of these semantic fields reflect, to a great extent, the focus of the 
topics of the interactions. The five domains of computer and technology, politics and military, transport and communication, medicine, and arts and education seem to be the most likely to borrow from with the dominance of the computer and technology domain over all others (18\%).

It has been remarked (Poplack, Sankoff, \& Miller 1988: 60) that "concentration of loanwords" in certain semantic fields are possibly "attributable to lexical need" in those fields. The fact that AML sometimes suffers from the lack of modern scientific and technical terminology is well known. Consequently, it is not surprising that non-indigenous items in these five categories are generally of technical and scientific nature; they are borrowed to fill conceptual gaps and urgent needs created by the introduction of new referents via the English-speaking world.

On the other hand, domains containing common and non-scientific items like those of clothing and fashion, animal and religious terms represent small proportion of the total. The motivation of lexical need appears to be peripheral here or approximately absent as in the case of the last two domains of animals and religion (both have 1\%).

In the case of such minor domains the areas of overlap nearly disappear because "the smaller and more specific the field, the more agreement there is among speakers on what words belong to the set" (Lehrer 1974: 17). Smaller domains are mutually distinguishable as for instance that fields of animals and religion; if something relates to the category of religion it is not an animal and vice versa.

Finally, in a given semantic domain "not all lexical items necessarily have the same status" and may therefore be ranked in terms of "markedness" (Finegan \& Besnier 1989: 179-80). In the medical field of AML, for example, terms like duktu:r 'doctor', mala:riya 'malaria', ?asbiri:n 'aspirin', and fi:tam:n 'vitamin' are regarded less marked (i.e. more usual) than the more marked terms like ji:nah 'gene' kulira 'cholera', ?insuli:n 'insulin', and bala:zma 'plasma'. The former set (the less marked) tends to be used more frequently in conversation and writing, easier to learn and remember, and often boarder in meaning than the latter set (the more marked). As an example illustrating the last point of comparison (i.e. broadness of meaning), the word duktu:r of the first group is the cover term of several occupations: 'a physician', 'a university teacher with a $\mathrm{PhD}$ ', and even 'a university instructor without a $\mathrm{PhD}$, while balazma of the second group refers only to that 'yellowish liquid part of blood'.

\subsection{Semantic change in AML borrowings}

Apart from its phonological and morphological structure, a word may be subjected to certain modifications in its meaning. These modifications or changes may be total or partial. Beside being "frequently unpredictable, semantic change seems to be "inevitable" (Pyles 1964). Words, whether native or loaned are most likely to undergo semantic changes in their original sense.

In the context of AML borrowings, the speed of scientific and technological progress in our time is making increasingly heavy demands on the language and the possibility of various types or categories of semantic change are being fully exploited. The most common of these categories, viz. "extension", "restriction", "amelioration", "pejoration", and "metaphorical extension" seem to be operating in AML loanwords from English. The degree of semantic change will not, however, be found to be uniform in all types, as some types seem to be more strongly represented than others. As we shall see, the directions of such changes in AML borrowings are in line with general observations put forward in the literature in this regard.

\subsubsection{Restriction}

The general tendency of semantic change in the overwhelming majority of AML borrowings is towards restriction. This tendency is seemingly natural in languages since it has been suggested that "extension is a less common process than restriction" (Ullmann 1983: 229). Hope (1963:41) further asserts that as a rule, the sphere of reference in the borrowing language is more restricted than in the language of origin. Examples of semantic narrowing in AML loanword corpus are listed in (2) below. Many English models are of multiple or polysemous senses, but when borrowed into AML they are usually charged only with one meaning (or maximally two meanings in some rare cases). In each case below, the original denotations are given as presented in "Longman Dictionary of Contemporary English" (LDCE), and the meaning acquired by a loanword is always "underlined".

a)

\section{?iskitš < sketch}

1. a simple drawing

2. $\quad$ a short humorous scene on stage, TV etc

3. a short written or spoken description

b) ba:lu:n < balloon

1. a small brightly coloured rubber bag filled with air and used as a toy or decoration

2. an aerostat

3. the circle drawn around the words spoken, by the characters

tira:nzi:t $<$ transit

1. the process of moving people (or goods) from one place to another

2. the movement of a planet in space 


\section{d) ?alu: < hello}

1. as a greeting

2. to answer the telephone or start a telephone conversation

3. to attract attention

4. to express surprise

e)

ka:bil < cable

1. a set of wires in rubber tube for carrying electricity or electronic signals

2. a thick strong metal rope used on ships

3. a cable television

4. a telegram

f)

mu:di:l < model

1. a small copy of building, etc.

2. someone whose job is to show clothes, etc.

3. a person employed to be painted, photographed, etc. by an artist

4. a person or thing regarded as excellent example to copy

5. a simple description of a system or structure

6. a particular type or design of a vehicle or machine.

g)

\section{ja:kit < jacket}

1. a short coat

2. a stiff paper that may fit over cover of a book, or a record.

3. a cover that surrounds and protects some types of machines

h) kabsu:lah < capsule

1. a tablet of medicine

2. a part of a spacecraft

i)

\section{ru:ti:n < routine}

1. the usual or regular way of doing things

2. a set of steps practiced by a dancer

3. a set of instructions given to a computer to perform specific operation

In this way the meaning of a loanword in AML covers only a small part of the sense it had in the original language (i.e. English). Moreover, the meaning covered is more often than not the most common one in the source language. Examples given above belong to some of AML semantic domains in the following order: entertainment, transport and communication, clothes, medicine and administration.

There are two cases in the data, however, that assume different manner of restriction. In fact, they are originally parts of English compound words. They are risi:far and diš/duš which only come to mean 'satellite receiver', and 'satellite dish', respectively, and have nothing to do with other lexical senses such as 'a telephone receiver', 'a plate, bowel', etc. In English dictionaries, such meanings are not included in the entries of the single words 'receiver' and 'dish'. They only mean so within a context, i.e. when the conversation is already dealing with satellite TV, etc. For the sake of linguistic simplification, Arab speakers seem to have chosen the main content-bearing word and use it to stand for the whole foreign compound.

\subsubsection{Extension}

The process of extension or generalization appears to be less common in AML borrowings where only seven extension cases are attested. This agrees with Ullmann and Hope's statements mentioned earlier. To begin with, the word ji:ns 'jeans' does not only mean 'trousers made of denim' (LDCE), but it has also been widened to refer to the cloth itself and to any garment (e.g. shirts, etc.) made of this material. The loanword wiski from 'whisky' has even acquired a broader sense than it did in English. In English it means 'a specific Irish/Scottish alcoholic drink distilled from barely' (LDCE), but in AML it came to mean 'wine or alcohol in general', though it may sometimes be used to denote that kind of spirits as well. taksi, 'taxi' which basically means 'a car rented for a journey; a cab' (LDCE), in AML it has come also to mean 'any small car which has the shape of a taxi'. In addition to its meaning as a place where money, blood, or data can be kept, the borrowed term bank 'bank' has recently developed a specific technical meaning, that is, 'the section of religious rulings' expressed by the compound banku l-fata:wa: literately meaning 'the bank of fatwas', following the patterns banku d-dam "blood bank" and banku l-ma3lu:ma:t 'data/information bank'. Originally, the word duktu:r from 'doctor' has the meanings of 'a physician' and 'a university teacher with a PhD' (LDCE), which are 
both in use in AML. What is interesting is that in university circles students call [duktu:r] any university instructor, even one who is not a $\mathrm{PhD}$ holder. It is worth mentioning that the first meaning (i.e. as a physician) has an Arabic equivalent (i.e. tabi:b), whereas the second has not. Finally, the word ku:kti:l, 'cocktail' seems to have undergone the same generalization process. It comes to refer to 'any variety of things (but of the same class)' and not only 'a mixture of drinks, fruit or food' (LDCE). Thus, this word may be employed in expressions like kukti:l min l-?aga:ni, lit. 'cocktail of songs' for 'a variety of songs', barna:maj ku:kti:l, lit. 'cocktail programme', for 'a TV, etc. programme that contains various items', and so forth. In this way, the loanword kukti:l is being used in a more abstract sense than the case with its original meanings.

From the examples cited above, it is clear that as soon as borrowed items have settled down in the lexicon of AML, only few cases show tendency towards greater extension. However, the tendency of semantic change in loanwords in JA appears to be the opposite where "instances of narrowing are less common in JA loanwords from English and French than cases of widening" (Bader 1990: 40).

\subsubsection{Pejoration and amelioration}

Aside from being narrowed or widened, the meaning of a loanword may be deteriorated or elevated in one way or the other. Ameliorative developments, as Ullmann (1983: 233) points out "have received less attention than pejorative ones, and on the whole they seem to be less frequent". AML loanwords show the same trend where instances of pejoration are more abundant than amelioration cases.

Examples of pejoration include the words hulyu:d 'Hollywood', si:nama: 'cinema', and dijital 'digital (satellite receiver)'. These words have the derogatory connotation of 'bad' or even 'immoral' because such words are dealt with in Arabic societies as the source and means of many obscene movies and corrupt programmes. The loanword lu:bi, from 'lobby' which most generally means 'group practicing negative pressure' as in ?al-lu:bi ş-şahyu:niyy 'the Zionist Lobby' commonly referred to in Arabic news media as exerting pressure on the American Administration and Congress to adopt anti-Arab and pro-Israeli positions. Similarly, bibsi 'Pepsi' and ku:ka ku:la 'Coca Cola' are believed on the part of Arab speakers to be names for products of Israeli or Israeli-based companies. The two words, therefore, are psychologically associated with the ideas of occupation and Zionism (the word Zionism whose Arabicized form is şahyu:niyyah is often pejoratively used to mean 'racism' in Arabic speech communities), and recently have evoked the desire of 'avoidance' and sometimes of 'boycott' of such products. The word sikirti:r 'secretary' remains a good instance of social prejudice against certain occupations. This word has acquired a deteriorative sense when we talk, for example, about a person higher in rank than a secretary but who appears to be doing the work of a secretary. Thus, one may say about a vice or assistant manager who carries out his superior's order without question ya3mal sikirti:r 3indah, i.e. 'he works as a secretary with him'.

In the case of amelioration, the examples are few. The loan ji:ns 'jeans' has the connotation of 'fashionable, modern' among younger people. Another example is fillah 'villa', which in English means 'a big country house with large gardens' (LDCE), has come to mean 'elegant and spacious house, usually on the outskirts of a city'. This word is sometimes used to express elevation when someone says about a flat ha: ¿ihi fillah, literally 'this is a villa' to suggest that the flat is elegant and spacious.

\subsubsection{Metaphorical extension}

A metaphor is a natural device potentially undergone by every word. AML loanwords may sometimes be extended figuratively to express some specific meanings. In this process a certain bundle of features in the original meaning of a borrowed item are replaced by another group of features. More often than not, the practice is that [-human] and [cognitive] are substituted by [+human] and [+cognitive]. This practice is in line with that of Arabic dialects (see Bader 1990).

Thus, the word di:na:mu: 'dynamo' usually suggests the meanings of 'energy', and 'vitality'. When a person is described as dinamu: l-fari:q i.e. 'dynamo of the team' (in a football match, for example), it means that 'he is the most essential, most energic, and most active'. In the same way kumbiyu:tar 'computer' is often metaphorically transferred to mean 'very intelligent or quick-witted person'. The two loans di:nasu:r 'dinosaur' and gurilla 'gorilla' may additionally mean 'huge person'. Occasionally, the word ?ulbu:m 'album' is employed metaphorically in expressions like ?ulbu:mu dikraya:t, and ?ulbu:mu ţ-ţufu:lah, i.e. 'the album of life' and 'the album of childhood', respectively.

Finally, there is the loanword ?al-kunturu:l from 'control' whose semantic change is different from the class of words cited earlier, but still involves the so-called 'metaphorical shift'. In AML, this word has surprisingly come to mean 'a section or department of examination/evaluation in school, university, or even in the Ministry of Education' in Arab Gulf states. This particular meaning, which does not exist in English, has most probably undergone a partial shift, i.e. the word ?al-kunturu:l has taken on a partially new but related meaning. This is the only example of shift attested in present data.

In concluding this section, it is important to note that there are no cases of semantic shift are attested in AML loanword data. A shift of meaning usually takes place when a given loanword is assigned a new meaning (cf. Bader 1990:41- 42). This can be explained by the fact that being a standard variety of Arabic, the incorporation of almost all foreign elements is usually made formally by Arabic academies which in turn try to import only the necessary denotations of referents from the lending languages. On the other hand, in Arabic spoken colloquials like JA, speakers play a crucial role in modifying the meaning of loanwords and they don't subject to any linguistic restrictions that are followed by Arabic academies. 
5.2.5 Possible factors to semantic change in AML borrowings

Pyles (1964: 306) points out that "while frequently unpredictable" change of meaning "is not wholly chaotic". This indicates that semantic change involves some kind of regularity, where it is possible, to some extent, to trace the various factors leadings to semantic changes in the words of a language. Ullmann (1983: 210), for example, maintains that the causes of semantic change could be: i) linguistic, ii) historical, iii) social, iv) psychological, v) due to foreign influence, and vi) due to a need for a new name.

Based on these facts and in the light of examples given for the different processes of semantic modification in AML loanwords, the attempt is made here to identify the possible reasons of semantic change in AML borrowings.

In dealing with the vocabulary of a language in general, the factor of need in (vi) above may be considered less important in comparison with other factors ( $\mathrm{i}-\mathrm{v}$ ). In the matter of semantic changes taking place in loanwords, however, this factor is highly predominant, especially in the case of restriction and extension processes. In this respect, Hope (1963) states:

Which aspects of the original signification are borrowed depends in some degree upon the borrowing language's need; the exigencies dictate what new meanings a borrowed word will acquire during the period immediately following its initial adoption - the period of acclimatization, between the moment of borrowing and full integration into the language. During this interval semantic change is rapid. (Hope 1963: 41)

In addition to lexical need, other factors like semantic similarity, social and psychological factors are found responsible for the change of meaning in AML loanwords, as will be elaborated below (see Bader 1990).

In most cases of restriction, need appears to be the potent factor at interplay in loanword narrowing. Words like mu:di:l, kabsu:lah, ba:lu:n, tira:nzi:t, ru:t:n etc. have no Arabic equivalents in AML and, therefore, were borrowed to denote an object or concept taken over from the culture associated with English. Usually, one meaning is needed in each case to serve as a specific purpose in a specific fixed context. This is the reason why the phenomenon of polysemia is seldom attested in loanwords and the main trend of semantic changes is towards restriction.

It is not clear, however, why a loanword like ?alu: is used in the sense 'to reply the telephone and initiate telephone conversations', whereas AML na3am 'yes', marhaba 'welcome' can be used instead. Basically, this word is used mainly in the spoken form of AML and most likely has come into the language via the regional dialects. So, it could be that social factors (e.g. prestige) play a role in the case of ?alu:

So far as extension cases are concerned, the factors of need and semantic similarity may be involved to justify the generalization in meaning. A good example is the word duktu:r whose sense has widened to refer also to 'university instructors without Ph.D degrees', since AML has no equivalent in use for this meaning. The semantic similarity between university professors and other instructors without $\mathrm{PhD}$ is obvious. The criteria of semantic similarity and need may be behind the additional meanings acquired by other words like taksi and ji:ns.

With the factor of need in mind, it is difficult to see why a word like wiski has been employed to mean 'alcohol or wine in general', while AML has the native xamr which can express exactly the same sense. Instead, psychological considerations may be hypothesized in this case. Some may have, consciously or unconsciously, thought that a word

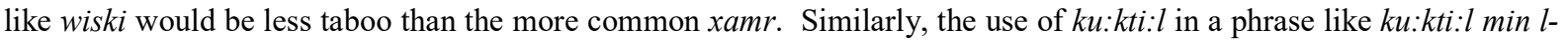
bara:mij, i.e. 'a variety of programmes', though AML majmu:3ah 'group', taški:lah 'variety' can be used in this place, is perhaps extended as such to express prestigious trends, particularly on the part of Arabic mass media.

In the case of pejorative and ameliorative developments, the factor of semantic similarity appears to be influential. A striking example at point is the loanword lu:bi. It is easy to realize the similarities between one of the original meanings of this word in English, i.e. 'group of people who try to influence members to support or oppose proposed legislation', and the more degenerative meaning it has developed in AML, i.e. 'group exerting negative political pressure'. The need of modern Arabic news media for a word conveying the latter meaning may be another reason behind the pejorative development.

Semantic similarity may also be behind the negative connotations of dijital, si:nama:, and hulyu:d as 'bad' and 'immoral' because the content of such sources is often corrupt and vile. It seems, however, that there is no room for the need criteria here, since AML is rich in synonyms meaning 'bad' or 'immoral' such as sayyi?, la:?axla:qiyy, munћaţ, etc. Another factor of social nature can be proposed here, too; it is the willingness of the Arab speakers to use such terms figuratively to express bad feelings in terms of features of modern life.

Social prejudice against certain classes and occupations may also participate in degrading the meaning of many words. An example at point is the word sikirti:r. This type of occupation is usually looked at with less respect in the Arab societies.

In all cases of metaphorical extension, semantic similarity is decisive, or rather the essence of metaphor device on a whole. On the other hand, the factor of need is totally absent here due to the fact that AML has numerous words meaning 'energic/ essential' (di:na:mu:), 'intelligent' (kumbiyu:tar), and 'huge' (di:naşu:r, and gu:rilla). Re-call that the words in parentheses are employed metaphorically to convey the meaning indicated. In terms of semantic similarity, it is obvious to notice the characteristic of size common to 'dinosaur' and 'gorilla' on one hand and a huge person on the other, the resemblance between 'computer' and 'clever person', and finally the vitality between 'dynamo' and 'energetic person'. 
At another level, there is a particular group of factors, which is often adopted to explain lexical change in general, and semantic change in loanwords in particular. These factors, which stated for example, in McArthur (1992: 576), and discussed in some detail in Sharma (1980: 93-94), are i) ignorance, ii) laziness (or laxity) and iii) misapprehension. As Sharma explains, ignorance mean that the borrower is most likely not conversant with the real sense of the word and consequently understands wrongly the sense in a smaller or greater measure. Laxity, for its turn, means that most of people are by nature not very particular about exact significations or shades of meaning of words, and usually select the part of the meaning only which had made impression upon their minds. Finally, misapprehension means that on hearing a word for the first time, we as usual derive its meaning from the context. The meaning thus obtained by guesswork may be wrong or partially correct. As such it is more likely that a wrong meaning is attached to such a word, if not explained or interpreted in another context in future.

It is important, however, to note that these factors may largely operate in a language whose bilinguals come, in realspeaking situations, into contact with foreign languages, i.e. a language whose loanwords have been acquired through spoken channels. In a standard variety like AML used in AGSNs (which is not a totally spoken variety), therefore, the influence of such factors remains marginal if not at all absent. In AML most borrowed items (especially the technical and scientific ones) are carefully and selectively incorporated into the language under the supervision of various Arabic academies and highly educated and specialized individuals. This is why the occurrence of semantic shifts in AML language is so scarce.

It can be then suggested that the same set of causes may best play a role in purely spoken languages like the various Arabic colloquials. For example, laxity and misapprehension may be behind the rendition of English 'satellite dish' and 'satellite receiver' mentioned earlier as diš/duš and risi:far in many spoken dialects of Arabic where, in the diglossic setting of Arabic, these two words have come into use in standard AML.

\subsection{The phenomenon of synonymy as a consequence of lexical borrowing}

For many semanticists (e.g. Ullmann 1983, and Palmer 1996) synonymy is usually related to the idea of "sameness of meaning" which is testable in terms of "substitutability and opposition" and where the occurrence of "true or exact" synonyms, if not completely possible, is at least too rare.

The profusion of synonyms in a language is undoubtedly one aspect of its linguistic richness. To a great extent, Arabic enjoys a wider range of synonymously related lexical items either in nouns, adjectives or verbs as compared to its Semitic sisters or other languages of the world (see Wafi 1945: 168-9). Having their place in AML dictionaries, loanwords that have "Arabic equivalents" do contribute to the phenomenon of synonymy in the language. In fact this phenomenon results from the two simultaneous processes of lexical borrowing and the modern effort of deriving equivalent neologisms, particularly in the language of science and technology.

As it will be illustrated below, the newly created terms by the second process (derivation or ?ištiqa:q) represent, in many cases, a real burden over the lexicon and turn to be redundant and problematic.

Synonyms in general can be classified into groups or patterns according to the underlying factors behind them (Palmer 1996: 88-90). Synonymy may take place due to i) the geographically divergent dialects or varieties of a language, ii) the difference in the emotive and evaluative meanings of words, iii) the existence of two or more different stylistic registers, and iv) lexical borrowing.

The English words 'fall' and 'autumn' are synonymous due to the fact that each one has its own geographical domain, the first is used in the United States and the second in Britain. Similarly, in AML and for some historical reasons we find two complete systems of the months of the calendar: the foreign (January, February, etc) and the traditional Semitic (Tammu:z, Aa:b, etc.). The latter system is followed in certain countries of the Middle East (Iraq, Syria, Lebanon, Palestine and Jordan) while the former one in other Arab countries.

Sometimes two words may have the same referential (or cognitive) meaning. In this case, they can be differentiated only in terms of their emotive and evaluative meaning. Words like 'statesman' and 'politician' (and even their Arabic correspondents, rajulu dawlah and siya:siyy) may differ in that the first suggests 'the sense of appreciation' while the second evokes 'the sense of cleverness and cunning'. As Palmer (1996: 90) notes that the approval or disapproval effect of such words functions as to influence attitudes.

The use of synonyms becomes also significant when employed to distinguish between two different registers. A good example at point can be drawn from AML. In the specific domain of military ranks, the foreign (Arabicized) terms like jinara:l 'general', kuluni:l 'colonel', etc. are used alongside with Arabic equivalents liwa:?, 3aqi:d, etc. Thus, the borrowing is said to be motivated by a desire for synonyms to distinguish registers; while the borrowed set is used to designate non-Arab officers (e.g. ?al-jinara:lu l-?amri:kiyy biliks 'the American General Blex'), the native set is used to refer to Arab military officers (e.g. ?al-liwa:?u š-ša:ðili 'the General ?aš-ša:ðili (of Egypt)).

Synonyms may result from the co-existence of native and foreign terms as a sequence of lexical borrowing in a language-contact situation. This process represents a major source of synonymic words. It has often been suggested, for instance, that "English is particularly rich in synonyms for the historical reason that its vocabulary has come from two different sources, from Anglo-Saxon (as native) on one hand, and from French, Latin and Greek (as foreign) on the other" (Palmer 1996: 88). Thus, the English synonymous pairs like 'kingly/royal', 'world/universe', 'time/epoch', 'rise/mount', result from English having borrowed the second term of each pair from French, Latin or Greek where the first element is native. In AML, the phenomenon of synonymy due to lexical borrowing from English and other 
European languages does exist. However, it is somewhat limited owing to some peculiarities pertaining to the nature of foreign elements borrowed and the linguistic reaction towards them.

AML reaction to loanwords that have already entered its lexicon can be generally realized in three ways. Loanwords in AML either: i) have no Arabic equivalents, ii) do have native equivalents, or iii) have been abandoned, or, so to speak, rejected and ultimately replaced by their Arabic equivalents.

Loanwords, which enjoy a stable position in AML lexicon and have no native counterparts, constitute more than three quarters of AML loanword data. These include all borrowings from the domain of weight and measurement, the majority of terms associated to computer hardware and software, and tremendous number of loans from other various domains such as ?asmant, 'cement', film 'film', si:na:riyu: 'scenario', ša:mbu: 'shampoo', milya:r 'milliard', ra:da:r 'radar', kulira 'cholera' takti:k 'tactic', ?aysikri:m 'ice-cream', etc.

If the previous group of (i) is at one end of a scale, the group in (iii) occupies the other end, where many loanwords have become obsolete. The alternatively coined AML neologisms seem to have gained, after a considerable period of time, greater frequency and popularity over the foreign items, and thus have replaced them. These neologisms are ordinarily invented by means of the analogical derivation, loan translations (calques) and semantic extension (or semantic loans). Examples of English loans that have been rejected by AML are listed in (3) below.

Obsolete loans

?utumbi:l
?utubi:s
ja:m

tiraktu:r

?irya:l

kandayšan

'automobile'
'autobus'
'jam'
'tractor'
aerial
'(air-) conditioning'
een where loanwords and
one synonymic neologism as
'telephone'
'disc (computer)'
'petrol'
'visa'
'anaemia'

AML neologism 1

ţa:?irah mirwahiyyah

$\hbar a: s u: b$

darbat jaza:?
AML equivalents

sayyarah

ha:filah

murabba

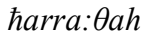

hawa:?iyy

mukayyif

Group (ii) represents a case in between where loanwords and their AML correspondents are both in use, and thus lead to the phenomenon of synonymy. This group of loanwords contributes nearly the remaining fourth of the present data. In most cases, a loanword may have one synonymic neologism as in (4a) and some other may have two as in (4b).

(4)

\section{b. Arabicized loanword \\ hiluku:btar 'helicopter' \\ kumbiyu:tar 'computer' \\ balanti 'penalty' (football)}

\author{
AML neologism \\ ha:tif \\ qurş (şalb) \\ naft \\ ta?ši:rat (duxu:l) \\ faqr damm
}

It is worth mentioning that the sameness of meaning between such synonyms in (4) is not total, that is, they do not often represent exact synonyms. For example, the word hatif and disk in expressions like ?al-ha:tif min ba3i:d and qurşu $\hat{s}$ sams never mean 'the telephone' and 'the disc of computer'. They rather come to mean 'the invisible caller/voice' and 'the disc of the sun', respectively. So, words like these are said to be synonymous only in some linguistic contexts and the claim of complete synonymy in such cases is a sort of exaggeration.

It has been claimed (for example, Ullmann 1983: 145) that in a language like English and in most synonymic situations the native (Anglo-Saxon) word shows informality, simplicity and homeliness whereas its foreign counterparts has the overtone of learning and formality and even of abstruseness. With respect to AML native-foreign synonymous pairs, the situation is relatively the opposite; in the diglossic situation of Arabic language, AML is looked at as the highly formal variety as opposed to regional dialects. As a general tendency among Arab speakers, foreign words in AML are considered semi-colloquial and elements of contamination. Moreover, almost all loanwords designate non-indigenous referents and only have been borrowed to fill lexical need, especially in science and technology. It seems that loanwords in AML are never motivated by stylistic or extra-linguistic factors. In comparison with their foreign counterparts, native words are considered more formal, more pretentious and more abstruse in phrases like the ones shown in (5) below. Like the case in English, AML native words have the emotive sense of warmth and homeliness. 
(5)

wiza:ratu n-nafți wa l-ma3a:din
wiza:ratu l-bitru:li wa lma3a:din
?itişa:lun ha:tifiyy
?itişa:lun tilifu:niyy
rukka:bu l-ha:filah
rukka:bu l-ba:ş

\author{
'Ministry of Petrol and Minerals' \\ 'a telephone call' \\ 'passengers of the bus'
}

There are some other cases of synonymy where the number of synonymic neologisms of a single borrowed word (or concept) may exceed ten cases. On one hand, it is a sign of Arabic versatile ability in coining multiple synonyms for a single foreign term, but it is a heavy and problematic burden over its lexicon, on the other. Stetkevych (1970:28) vividly observes, "the modern Arabic lexicon sometimes suffers as much from a super abundance of synonymous terms as it does from the lack of new vocabulary ... and becomes unruly if not altogether useless in a language which aims at terminological precision". An interesting example is the eleven synonymous neologisms invented for the term 'brake' as counted by al-Shihaabi (1961) and cited in Stetkevych (1970:28-29). Seven of them are listed in (6) below with the sources by which these neologisms were proposed. Note that the English 'brake' is not borrowed by standard AML, though it is so common in many dialects of Arabic (e.g. in Yemeni Arabic).

(6) Some synonymic equivalents of the term 'brake'.

\section{Neologism}

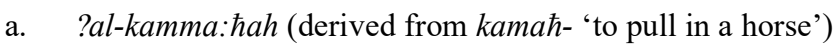

b. ?al-mu:qif

c. ma:sik

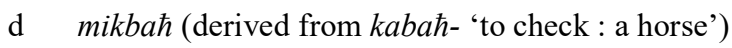

e. ?al-mi:qaf

f. $a:$ biţah

g. ?al-farmalah

\section{Source/ Neologizer}

Cairo Academy

Iraq

Syria

Syria

A technical book

The English-Arabic Dictionary by A. Elias

Cairo Academy

Most of these synonyms have been abandoned, and what have remained in actual use are the terms in (6d), and (6g), which have been slightly modified as ka:bih and fara:mil.

Another similar and interesting example is related to the recent rapidly developed device of wireless telecommunication, viz. 'the mobile phone'. The loanword mu:bayl is in actual use in Arabic along with six Arabic

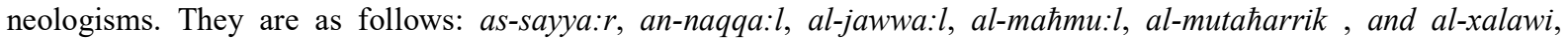
meaning literally 'locomotive', 'movable', 'roaming', 'carried', 'mobile', and 'cellular', respectively. In AGSNs, only three neologisms are used, namely al-jawwa:l, al-maћmu:l, and as-sayya:r. These terms may either be used alone, i.e. as single words; with the native word ha:tif 'telephone' or with the loanword tilifu:n. In the latter case, the resultant phrases come in the form of analyzed hybrid compound: tilifu:n sayya:r, tilifu:n naqqa:l, and so on. Beside the loanword mubayl, at least, two terms out of the six are used in each Arab country.

\title{
6. Conclusion
}

Loanword data are analyzed semantically and fifteen distinctive semantic domains have emerged. Domains that are related to terms of technical and scientific nature are found ranking much higher $(9 \%-18 \%)$ than those domains containing nontechnical elements $(1 \%-8 \%)$. The dominance of computer and technology category is enhanced by the lexical need felt by AML to fill conceptual gaps created by the introduction of new referents via the English-speaking world.

The meaning of English loans in AML is adapted in various degrees due to a number of different factors. Almost all common mechanisms of semantic change (extension, restriction, amelioration, pejoration, and metaphorical extension) are found at work in the context of AML borrowings. The directions of such changes in AML borrowings are consistent with the general observations put forward in the literature: instances of restriction and pejoration, on one hand, are much more abundant than that of extension and amelioration, on the other. Generally, the tendency of semantic change in the overwhelming majority of AML borrowings is towards restriction. Usually, one meaning is needed in each case to serve as a specific purpose in a specific fixed context. This is the reason why the phenomenon of polysemia is seldom attested in loanwords. Factors like need, semantic similarity, and factors of social and psychological considerations (e.g. prestige, taboo) seem to be the potent factors at interplay in semantic change, with the first two, i.e. need and semantic similarity, being the most common reasons in most types of semantic change. At another level, the influence of such factors like ignorance, laxity and misapprehension on the meaning of Arabicized words remains marginal if not at all absent. These factors usually operate in loanwords that are accommodated into a language through mainly spoken channels. In a standard variety like AML (which is not a totally spoken variety), most borrowed items (especially the 
technical and scientific ones) are carefully and selectively incorporated into the language under the supervision of various Arabic academies and highly educated and specialized individuals. This is why the occurrence of semantic shifts in AML language is so scarce. It can be then suggested that the same set of causes may best play a role in purely spoken languages like the various Arabic colloquials.

The problem of synonymy lies in those loanwords that have "Arabic equivalents" in the language (one fourth of loanword data). In fact, this phenomenon results from the two simultaneous processes of lexical borrowing and the modern efforts of deriving equivalent neologisms. The second process (derivation or ?ištiqa:q) represents, in many cases, a real burden over the lexicon and turns to be redundant and problematic. For example, the English 'mobile telephone' has six Arabic neologisms in addition to the loanword mu:bayl.

Finally, it has been found that calquing (loan translation) in Arabic is a highly productive method of lexical expansion. This process is an effective device at the hand of Arab neologizers and linguists to largely reduce the great impact of foreign borrowings on Arabic. Therefore, there is an urgent need to investigate the phenomenon of calquing and examine the various versatile and flexible abilities of creating calques in Arabic language. The actual adoption of this process will contribute to the solution of the problem of synonymy which usually occurs as a consequence of lexical borrowing.

\section{Acknowledgment}

This research paper has been funded by the Deanship of Scientific Research, Najran University, Saudi Arabia (Grant No. NU/SHED/14/173).

\section{References}

Abdul Razak, Z. (2011). Modern media Arabic: A study of word frequency in world affairs and sports sections in Arabic newspapers. An unpublished $\mathrm{PhD}$ thesis, University of Birmingham, Birmingham, UK.

Al abed, F. \& Smadi, O. (1996). "Spread of English and Westernization in Saudi Arabia". World Englishes, 15(3), 307317.

Al-Qinai, J. (2000). Morphophonemics of loanwords in Arabic. Studies in the Linguistic Sciences, 30(2), 1-25.

Al-Saidat, E. (2011). English Loanwords in Jordanian Arabic: Gender and number Assignment. Language Forum, 37 (1), 59- 72

Babrakzai, F. (2002). Is English a lingua franca in the Gulf? TESOL Arabia Perspectives, 10. p 1.

Bader, Y. (1990). Semantic Change in Arabic Loanwords from English and French. Abhath Al-Yarmouk Journal, 8 (2), $33-48$.

Boyle, R. (2011). Patterns of change in English as a lingua franca in the UAE. International Journal of Applied Linguistics, 21(2), 143- 161.

Boyle, R. (2012). Language contact in the United Arab Emirates. World Englishes, 31(3), 312- 330.

Heath, J. (1989). From Code-switching to Borrowing: Foreign and Diglossic Mixing in Moroccan Arabic. Kegan Paul: London.

Hope, T. (1963). Loan-words as Cultural and Lexical symbols. Archivum Linguisticum, 14, 111-121.

Jarrah, A. (2013). English Loan Words spoken by Madinah Hijazi Arabic Speakers. AWEJ Special issue on Translation, 2, 67-85.

Lehner, A. (1974). Semantic Fields and Lexical Structure. North-Holland Publishing Company: Amsterdam

Lehner, A. (1985). The influence of semantic fields on semantic change. In Jacek Fisiak (ed.), Historical Semantics, Historical Word Formation, 283- 296.

Longman Dictionary of Contemporary English, (2015). Pearson Education Limited, sixth edition.

Mahmoud, A. (2013). A linguistic perspective of the effect of English on MSA: Manifestations and ramifications. Journal of King Saud University - Languages and Translation, 25, 35-43.

McArthur, T. (1992). The Oxford Companion to the English Language. Oxford University Press: Oxford \& New york.

Newman, D. (2002). The European Influence on Arabic during the Nahda Lexical Borrowing from European Languages (ta'rib) in 19th-Century Literature', Arabic Language and Literature 5, pp. 1-32.

Palmer, F. (1996). Semantics. Cambridge University Press: Cambridge.

Poplack, S., Sankoff, D. \& Miller, C. (1988). The Social Correlates and Linguistic Processes of Lexical Borrowing and Assimilation. Linguistic, 26, 47-104.

Pyles, T. (1964). The Origins and Development of the English Language. Harcourt, Brace and World, INC.: New York.

Sankoff, G. (2001). Linguistic Outcomes of Language Contact. 2001. In Peter Trudgill, J. Chambers \& N. SchillingEstes, eds., Handbook of Sociolinguistics. Oxford: Basil Blackwell, 638-668. 
Sharma, D. (1980). A Study of Loan Words in Central Pahāri. R.K. Malhotra, Punjab University: Chandigarh.

Stetkevych, J. (1970). The Modern Arabic Literary Language: Lexical and Stylistic Developments. The University of Chicago Press: Chicago and London.

Thornburg, L. (1980). Arabic Loan Phonology: The Assimilation of English Lexical Items. Linguistics, 18,523-542

Ullmann, S. (1983). Semantics: An Introduction to the Science of Meaning. Billing and Sons Ltd.: Worcester.

Versteegh, K. (2009). Loan Verbs in Arabic and the Do-Construction. In T. Muraoka and C.H.M. Versteegh (eds.), Studies in Semitic Languages and Linguistics, 53, 187- 200.

Versteegh, K. (2010). Contact and the development of Arabic. In Raymond Hickey (ed.), The Handbook of Language Contact, Wiley-Blackwell.

Wafi, A. (1945). fiqhu l-lugah [Philology]. Dar al-Nahdhah: Cairo.

Weber, A. (2011). Politics of English in the Arabian Gulf. From proceedings of the $1^{\text {st }}$ International Conference on Foreign Language Teaching and Applied Linguistics, Sarajevo, May 5-7, 60- 66.

Witalisz, A. (2011). Linguistic Globalization as a Reflection of Cultural Changes. From proceedings of the 19th Annual Conference of the Global Awareness Society International, Jagiellonian University, Krakow, Poland, 1- 12 . 